\title{
Klippel-Feil Syndrome with Multiple Cervical Anomalies Discovered Following Trauma
}

\author{
Fernando Celi ${ }^{1}$ Giancarlo Saal-Zapata ${ }^{2,3}$ \\ ${ }^{1}$ Department of Neurosurgery, Hospital de Emergencias José \\ Casimiro Ulloa, Miraflores, Lima, Perú \\ ${ }^{2}$ Department of Neurosurgery, Hospital Nacional Guillermo \\ Almenara Irigoyen, La Victoria, Lima, Perú \\ ${ }^{3}$ Clínica Angloamericana, San Isidro, Lima, Perú
}

\author{
Address for correspondence Giancarlo Saal-Zapata, MD, Grau \\ Avenue 800, La Victoria, Lima 13, Perú \\ (e-mail: gian_carlo1987@hotmail.com,gsaal1987@gmail.com).
}

Indian J Neurotrauma:2021;18:69-71
Abstract
Keywords
- Klippel-Feil syndrome
- atlas
- vertebral artery
- cervical fracture
- anterior cervical
corpectomy and fusion

The approach to the upper cervical spine is a challenge for surgeons, not only for its complex anatomy but also for the great variety of pathologies. Klippel-Feil syndrome (KFS) is a congenital disease characterized by the fusion of two or more cervical segments and is associated with various musculoskeletal and vascular malformations. However, there is no consensus on the type of surgery, approach, level of fixation or fusion. We report the case of a KFS, associated with multiple anatomical variants, who suffered a traumatic cervical injury and underwent surgical treatment.

\section{Introduction}

The management of pathologies of the upper cervical spine is complex, not only due to the anatomy but also due to the diversity of pathologies (craniocervical junction, atlas, axis, ligaments and joints), which generate different approaches for surgical management. ${ }^{1}$

Klippel-Feil syndrome (KFS) is a congenital disease characterized by the fusion of two or more cervical segments and is associated with various musculoskeletal and vascular malformations, ${ }^{2,3}$ up to $50 \%$ of patients present the following triad: low posterior hairline, short neck, and limited cervical range of motion. ${ }^{2-4}$ Decreased movement due to congenital fusion of the cervical spine, in the long-term, causes stress on the fused segments and produces cervical hypermobility with a consequent increase in the instability of the cervical spine. ${ }^{2}$

We report the case of a KFS associated with an anomalous course of the vertebral artery, occipitalization of C1, luxation of the odontoid process and C3-C4 anterolisthesis, following trauma and surgical management.

\section{Case Report}

A 63-year-old male, with a history of a traffic accidents and whiplash syndrome 30 days before admission, presented

published online

October 9, 2020
DOI https://doi.org/

$10.1055 / \mathrm{s}-0040-1718245$

ISSN 0973-0508. moderate cervical pain and paresthesias of the left upper limb that lasted 3 days. Due to persistent symptoms and cervical pain (visual analog scale [VAS] 7/10), patient went to the emergency department.

Physical examination revealed cervical pain at the level C2C6 and paramedial, presence of low-posterior hairline, a wide and short neck with decreased range of motion at flexion, lateral flexion, extension, and rotation movements. Hypoesthesia in dermatomes $\mathrm{C} 3-\mathrm{C} 5$ of the left upper limb, limitation of movement of left shoulder to abduction, C5 myotome muscular strength in left upper limb $4 / 5$ and normal reflexes were found.

Radiological examination showed the cervical spine having lordosis, fusion of $\mathrm{C} 1$ and $\mathrm{C} 2$ and anterolisthesis $\mathrm{C} 3-\mathrm{C} 4$ ( $\sim$ Fig. 1A, 1C). CT of the cervical spine showed traces of nondisplaced fracture at the level of the right lateral mass of atlas, right lateral luxation of the odontoid process, $\mathrm{C} 3-\mathrm{C} 4$ grade I anterolisthesis and atlanto-occipital assimilation (-Fig. 1D, 1E).

CT angiography of carotid arteries showed a variation in the course of both vertebral arteries. Left vertebral artery was dominant, with a preatlas loop and the entrance to the skull was below $\mathrm{C} 1$. The right vertebral artery was hypoplastic, making its entrance to the skull below C1 directly (-Figs. 1F, 1I).

MRI of the cervical spine showed signs of ankylosis between the base of the skull and atlas, atlas and axis; C3-C4 grade I anterolisthesis, C2-C3 protruding hernia with 

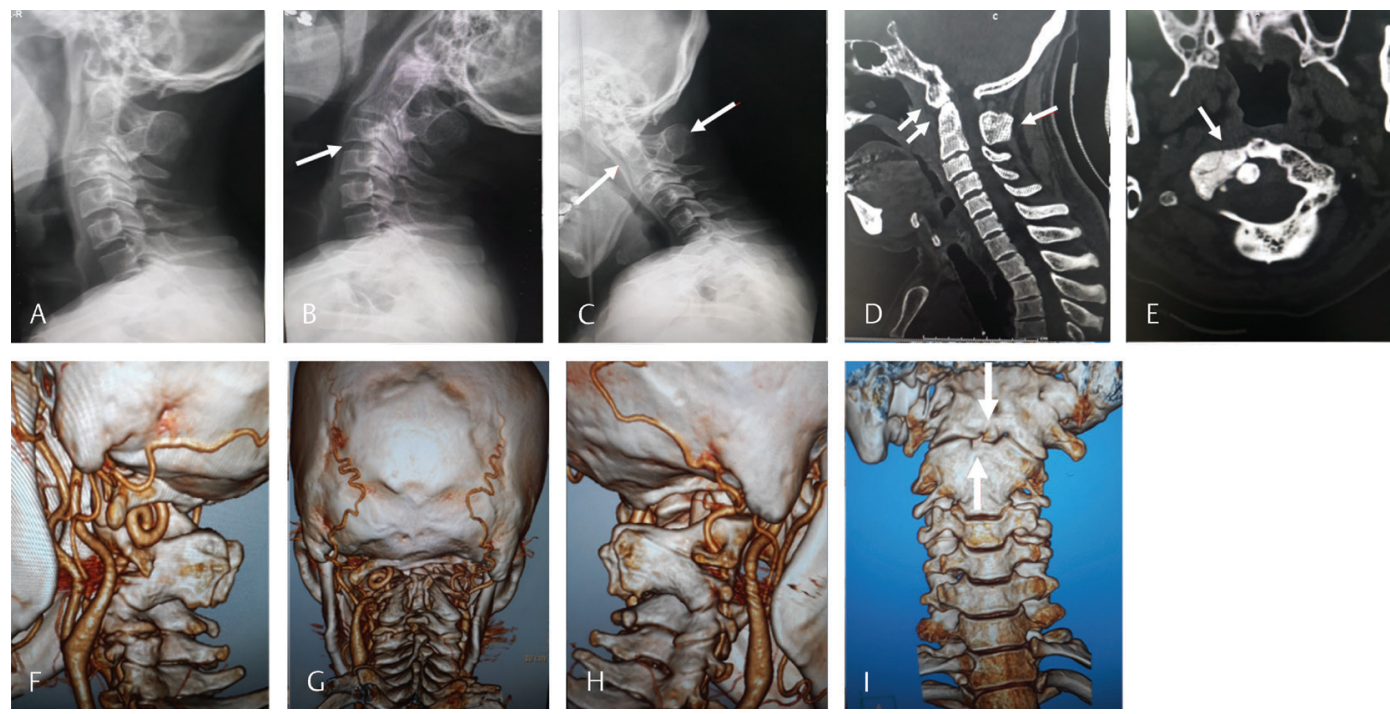

Fig. 1 (A-C) X-ray showing the cervical listhesis with instability (arrows) and fusion of vertebrae. (D) Sagittal CT scan revealing the occipitalization of C1 (double arrows) (E) Axial CT scan shows signs of an old fracture in the body of the atlas and the luxation of the odontoid process (arrow). (F-H) CTA with 3D reconstruction shows the anomalous course of the vertebral arteries. (I) Frontal view of the CTA with 3D reconstruction shows the fusion of the $\mathrm{C} 1$ and $\mathrm{C} 2$ vertebrae (thick arrows).

posterior osteophytes, and a hypertrophic yellow ligament, which conditioned a compressive myelopathy with edema at this level and spondyloarthrosic changes ( - Fig. 2A, 2B).

We decided to perform the anterolateral cervical approach (Smith and Robinson approach). The patient was in supine position with head traction. A left paramedian incision was made and usual dissection was performed. The $\mathrm{C} 3$ vertebra was identified and the corpectomy was followed by the placement of the implant. The bony structures were softer and easily resected. Finally, the anterior plate was placed. The identification of the correct levels was the major concern of the procedure.

After surgery, the patient made a gradual recovery with clinical improvement. VAS improved to 3/10 and the postoperative CT scan showed no complications ( - Fig. $2 \mathrm{C}$ ).

\section{Discussion}

Management of the upper cervical spine pathology is a challenge due to its complex anatomical characteristics and for the variety of existing surgical classifications and criteria such as those of AO Spine, German Society for Orthopedics and Trauma (DGOU), among others. ${ }^{5-7}$ Despite these criteria, there is no definitive consensus on the type of surgery, approach, level of fixation or fusion in patients with cervical injury; even less in patients with KFS. ${ }^{8,9}$

KFS is a genetic disease characterized by fusion of the cervical vertebrae, which generates decreased movement; in the long-term, it produces hypermobility and cervical instability, with a natural history that is not very clear. It presents a wide variety of symptoms and neurological signs, which are intensified when trauma occurs. ${ }^{10}$ Similar cases like this have been reported; authors like Yusuke, Mishima and others have published cervical fractures associated with KFS. ${ }^{11,12}$
Our case presented the classic triad: A short neck, decreased range of motion, and low-posterior hairline, which is seen in up to $50 \%$ of cases with KFS. $810,13,14$

Patients with KFS also present concomitantly with other congenital anomalies such as spina bifida, Arnold-Chiari, scoliosis, concurrent neuromuscular abnormality, Sprengel deformity, congenital torticollis, cardiovascular abnormalities, abnormalities of the urinary tract, and nervous system anomalies. ${ }^{3}$ Regarding vertebral artery anomalies, Patil et al reported an incidence between 3 and $8 \%$ of vertebral artery anomalies. ${ }^{15}$

Few articles have reported abnormalities of the vertebral artery; Ahmad et al reported a case of anomalous vertebral arteries in KFS with occipitalization of the atlas, ${ }^{16}$ similar to our patient, with the difference that in our case both vertebral arteries entered into the foramen below $\mathrm{C} 1$.

There are no exact guidelines indicating the best technique or approach in cervical injuries; however, criteria of instability or presence of neurological deficit in most of the guidelines are taken into account. ${ }^{5-7,9,17,18}$

When we decided the surgical technique in this patient, we also had to assess the total cost of the materials that would be used (patient did not have insurance). The technique used was the anterolateral cervical approach (Smith and Robinson approach) associated with C3 corpectomy, following the anatomical and surgical steps described in previous reports. ${ }^{19,20}$

Although there is no clear decision between an anterior and posterior approach, the anterior approach showed better postoperative outcomes, according to neurological recovery, compared with the posterior approach in patients with neurological deficit or cervical myelopathy. ${ }^{20}$

More studies are needed to determine the best surgical approach in these patients and monitor postoperative outcomes. 

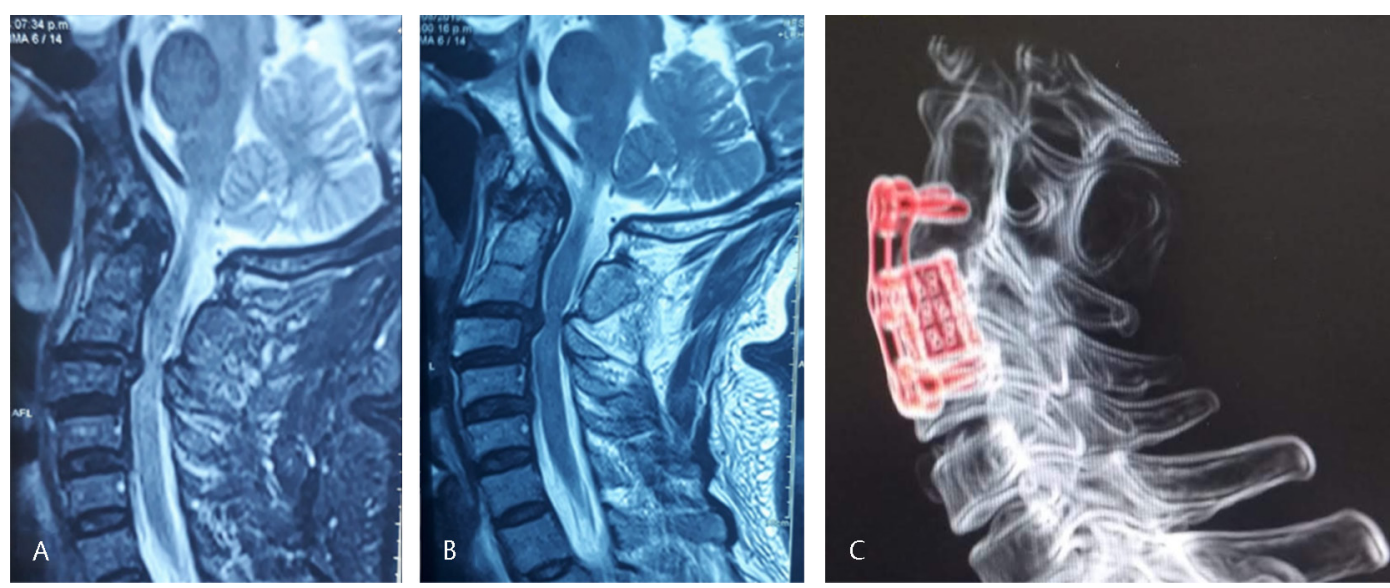

Fig. 2 (A, B) Preoperative cervical MRI showing the C2-C3 hernia, mild C3-C4 listhesis, and the hypertrophic yellow ligament generating myelopathic changes. (C) Postoperative cervical CT scan showing the final result after anterior cervical corpectomy and fusion (ACCF).

\section{Conclusion}

The management of cervical spine pathology is complex, as it will depend not only on the type of injury, but also on the comorbidities of each patient. KFS-associated trauma is a challenge for diagnosis and treatment due to the anatomical variations.

\section{Conflict of Interest}

None declared.

\section{References}

1 Bransford RJ, Alton TB, Patel AR, Bellabarba C. Upper cervical spine trauma. J Am Acad Orthop Surg 2014;22(11):718-729

2 Frikha R. Klippel-Feil syndrome: a review of the literature. Clin Dysmorphol 2020;29(1):35-37

3 Zhou PL, Poorman GW, Wang C, et al. Klippel-Feil: a constellation of diagnoses, a contemporary presentation, and recent national trends. J Craniovertebr Junction Spine 2019;10(3):133-138

4 Karasick D, Schweitzer ME, Vaccaro AR. The traumatized cervical spine in Klippel-Feil syndrome: imaging features. AJR Am J Roentgenol 1998;170(1):85-88

5 Gonschorek O, Vordemvenne T, Blattert T, Katscher S, Schnake KJ; Spine Section of the German Society for Orthopaedics and Trauma. Treatment of odontoid fractures: Recommendations of the Spine Section of the German Society for Orthopaedics and Trauma (DGOU) Global Spine J 2018;8(2, Suppl):12S-17S

6 Scholz M, Kandziora F, Kobbe P, Matschke S, Schleicher P, Josten C; Spine Section of the German Society for Orthopaedics and Trauma. Treatment of axis ring fractures: Recommendations of the Spine Section of the German Society for Orthopaedics and Trauma (DGOU) Global Spine J 2018;8(2, Suppl):18S-24S

7 Kandziora F, Scholz M, Pingel A, et al; Spine Section of the German Society for Orthopaedics and Trauma. Treatment of atlas fractures: Recommendations of the Spine Section of the German Society for Orthopaedics and Trauma (DGOU) Global Spine J 2018;8(2, Suppl):5S-11S

8 Nouri A, Tetreault L, Zamorano JJ, Mohanty CB, Fehlings MG. Prevalence of Klippel-Feil Syndrome in a surgical series of patients with cervical spondylotic myelopathy: analysis of the prospective, multicenter AOSpine North America Study. Global Spine J 2015;5(4):294-299

9 Yin Y-H, Qiao G-Y, Yu X-G. Surgical treatment of occipitocervical dislocation with atlas assimilation and Klippel-Feil syndrome using occipitalized C1 lateral mass and C2 fixation and reduction technique. World Neurosurg 2016;95:46-52

10 Al-Tamimi YZ, Sinha P, Ivanov M, Robson C, Goomany A, Timothy J. Fracture through fused cervical segments following trauma in a patient with Klippel-Feil syndrome. $\mathrm{Br} \mathrm{J}$ Neurosurg 2014;28(3):408-410

11 Dodo Y, Kudo Y, Ishikawa K, et al. Fracture-dislocation of the cervical spine secondary to low-impact trauma in a patient with Klippel-Feil syndrome: a case report. Spine Surg Relat Res 2019;4(1):84-86

12 Mishima K, Itoi A, Sugita M, Yanagawa Y. A case of fracture through fused cervical segments following trauma in a patient with Klippel-Feil syndrome. J Emerg Trauma Shock 2016;9(2):85-86

13 Gruber J, Saleh A, Bakhsh W, Rubery PT, Mesfin A. The prevalence of Klippel-Feil Syndrome: a computed tomography-based analysis of 2,917 Patients. Spine Deform 2018;6(4):448-453

14 Samartzis D, Kalluri P, Herman J, Lubicky JP, Shen FH. “Clinical triad" findings in pediatric Klippel-Feil patients. Scoliosis Spinal Disord 2016;11:15

15 Patil PV, Patil AM, Apte AV, Attarde VY. Anomalous origin of left vertebral artery from carotid bulb seen as "trifurcation" of left common carotid artery with acute infarct in ipsilateral thalamus: a case report. J Neuroimaging 2015;25(4):662-664

16 Mubarak AI, Morani AC. Anomalous vertebral arteries in Klippel-Feil syndrome with occipitalized atlas: CT angiography. Radiol Case Rep 2018;13(2):434-436

17 Ghogawala Z. Anterior cervical option to manage degenerative cervical myelopathy. Neurosurg Clin N Am 2018;29(1):83-89

18 Liu X, Min S, Zhang H, Zhou Z, Wang H, Jin A. Anterior corpectomy versus posterior laminoplasty for multilevel cervical myelopathy: a systematic review and meta-analysis. Eur Spine J 2014;23(2):362-372

19 Cheung KMC, Mak KC, Luk KD. Anterior approach to cervical spine. Spine 2012;37(5):E297-E302

20 Luo J, Cao K, Huang S, et al. Comparison of anterior approach versus posterior approach for the treatment of multilevel cervical spondylotic myelopathy. Eur Spine J 2015;24(8):1621-1630 